\title{
Effect of Cortex Lycii Radicis Ethanol-Extract on the Hypoglycemic and Hypolipidemic In Type 2 Diabetic Rats
}

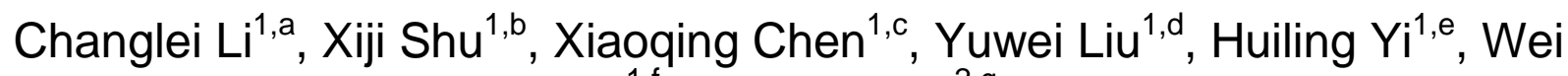 \\ $\mathrm{Liu}^{1, \mathrm{f}}$, Baomiao $\mathrm{Ma}^{2, g_{*}}$ \\ ${ }^{1}$ School of Medicine, Jianghan University, Wuhan 430056, China \\ ${ }^{2}$ Wuhan Institutes of Biomedical Sciences, Jianghan University, Wuhan 430056, China \\ aemail:licl.jhun@foxmail.com; bemail: shuxiij@sina.com; 'email:8298921@qq.com; \\ demail: 304077545@qq.com; email: 349351667@qq.com; \\ femail: 66130993@qq.com; '9email: mabm.whibs@aliyun.com; *Corresponding author
}

Keywords: Cortex lycii radicis ethanol-extract, Type 2 diabetic mellitus(T2DM), Hypoglycemic, Hypolipidemic

\begin{abstract}
To observe effect of cortex lycii radicis ethanol-extract on the hypoglycemic and hypolipidemic in T2DM rats. T2DM rat modelinduced by intravenous injection small dose of streptozotocin (STZ) and feeding high fat-high glucose diet .The rats were randomly divided into blank control group, model control group, cortex lycii radicis ethanol-extract groups of high dose, medium dose and low dose, positive drug rosiglitazone group. Seven weeks after medication, to observe influence of cortex lycii radicis ethanol-extract on rat weight and the content in fasting blood glucose (FBG), serum insulin(INS), total cholesterol(TC), triglycerides(TG) and low density lipoprotein cholesterol (LDL-C). Compared blank control group with the other groups, there were no significant differences in various indicators of be detected $(P>0.05)$. Compared with the model group, cortex lycii radicis ethanol-extract can reduced body weight, FBG, INS, TC, TG and LDL-C, increased INS of T2DM rats, the differences were significant $(\mathrm{P}<0.01$ or 0.05$)$.Cortex lycii radicis ethanol-extract can lowers blood glucose and regulate blood lipid metabolism to some extent.
\end{abstract}

\section{Introduction}

Cortex lycii radicis, alias were wolfberry bark, which was dry root bark of Lycium chinensis. It main producing area were Shanxi, Henan, Zhejiang, Jiangsu, and so on. Taste sweet and potency cool. Attributed to lung, liver and kidney. It's function was clearing deficient heat, purte the white and cooling blood. Clinically for treatment some diseases, such as osteopyrexia sweats, feirekechuan, hematemesis, bleeding from five sense organs or subcutaneous tissue, bloody stranguria, hypertension, carbuncle swollen, malignant sores, and so on. Modern pharmacological studied shown that lycii radicis has a variety of effects such hypoglycemic ${ }^{[1]}$, lower the blood pressure and blood fat $^{[2]}$, antibacterial and antiviral ${ }^{[3]}$, antipyretic-analgesic ${ }^{[4]}$, immunologic enhancement $^{[5]}$ etc. Therefore, the drug has a potential advantage in the treatment of diabetes.The aim of this study is through to observe the effect of content of cortex lycii radicis ethanol-extract on T2DM rat weight, FBG, INS, TC, TG and LDL-C, to further clarify its pharmacological effect on T2DM,which provide theoretical basis for the PCM prevention and treatment of diabetes.

\section{Materials and methods}

Animals. A total of 70 SPF SD male rats, and their body weight were $220 \pm 20$ g, whom were conventional breed in barrier environment, eating and drinking with free state. Feed are common feed and high fat-high sugar diet.

Reagents and instruments. The preparation process of cortex lycii radicis alcohol-extrac:take 500 g cortex lycii powder which be soaked about $24 \mathrm{~h}$ in $80 \%$ alcohol, connected the circulating cool water, reflux extraction at $78^{\circ} \mathrm{C}$ for $1 \mathrm{~h}$, filter liquid and extracting twice, combined filtrate and the 
filtrate be vacuum concentration by rotary evaporation apparatus at $55^{\circ} \mathrm{C}$, the concentration of the crude drug is $3 \mathrm{~g} \cdot \mathrm{mL}^{-1}$, in accordance with the different doses to dilute the reserve with distilled water, respectively ${ }^{[1,6]}$.

Streptozotocin, rosiglitazone, glucose, blood glucose meter, triglyceride assay kit, total cholesterol assay kit, low density lipoprotein ELISA kit, glycosylated serum protein assay kit, insulin radioimmuno assay kit, and so on.

Modeling and packet administration. 70 healthy rats were fed with suitability one week after, whom were weighed and randomized groups. There were 10 rats in the blank control group and be fed with common feed; the remaining 60 rats were injected STZ from tail vein at a dose of 30mg/kg for one time, STZ contains citric acid and sodium citrate buffer solution (PH4.4) and the ratio was 1:1.32. Rats were not prohibit water but fasted for $12 \mathrm{~h}$ before injecte the STZ, after that, whom be feed with high fat-high sugar diet. After the rats be fed for three weeks, take the blood from tail vein to measured the random FBG, after interval 2 days, 60 rats were fasting for $8 \mathrm{~h}$, take blood form after the ball and isolated serum to measure FBG and INS. The success criteria of T2DM model rats is the blood glucose level $\geqq 10 \mathrm{mmol} \cdot \mathrm{L}^{-1[7]}$. After testing, a total of 58 rats were produced model with successfully. Screened from 50 rats, randomly divided into model group, cortex lycii radicis ethanol-extract groups of high dose, medium dose and low dose, rosiglitazone group, 10 rats in each group.The blood sugar of blank control group rats were normal.

Initiation of administration after the model was made with successfully, blank control group and model control group be given saline at a dose of $10 \mathrm{~mL} /(\mathrm{kg} \cdot \mathrm{d})$ with lavage, positive control group be given rosiglitazone at a dose of $10 \mathrm{~mL} /(\mathrm{kg} \cdot \mathrm{d})$ with lavage, cortex lycii radicis ethanol -extract high dose group (high alcohol group), cortex lycii radicis ethanol-extract medium dose group (medium alcohol group), cortex lycii radicis ethanol-extract low dose group (low alcohol group) rat be given cortex lycii radicis ethanol-extract at a dose of $20 \mathrm{~mL} /(\mathrm{kg} \cdot \mathrm{d}), 10 \mathrm{~mL} /(\mathrm{kg} \cdot \mathrm{d}), 5$ $\mathrm{mL} /(\mathrm{kg} \cdot \mathrm{d})$ with lavage respectively. Drug treatment period for 7 weeks, one time a day, during the time, the rats in each group without death. Rats in each group all be fasting can not help but water 12h before administration of the experiment and after the last administration, take blood form after the ball with limosis in the morning, after administration, all rats were killed. The blood was placed in Eppendorf which preparation beforehand and storagef or $4 \mathrm{~h}$ at $4{ }^{\circ} \mathrm{C}$, which were put into the low temperature centrifuge with 4000 revolutions per minute and work for $15 \mathrm{~m}$, separate out the supernatant, which be packed and preservated into $-20^{\circ} \mathrm{C}$ environment for detection and analysis.

Detection indicators. All the indicators were detected before and after administration. First, body weights of the rats. Second, the values of FBG concentration were measured by using the Sino blood glucose meter. Third, follow the instructions to detect the INS content. According to the enzyme assay to detect the TG and TC of serum. By using SUR method to detect the LDL-C.

Statistical Analysis. Using SPSS 13.0 software for statistical analysis of the obtained data, the results of indicators were expressed by $\bar{x} \pm s$, significance test using the $t$ test and ANOVA. With $P<0.05$ was considered statistically significant and $P<0.01$ as statistically significant difference.

\section{Results}

Weight and the content in FBG and INS effects of cortex lycii radicis ethanol-extract on T2DM rats. Weight: before administration, the values of each group were all higher than those in blank group, the differences were significant $(P<0.05)$. FBG: before administration, the values of each group were all higher than those in blank group, the differences were significant $(P<0.01)$. After administration: the values of each group were all higher than those in blank group, however, only the values of model group and rosiglitazone group were higher than those in blank group, the differences were significant $(P<0.05$ or $P<0.01)$, the values of high, medium, low alcohol group and rosiglitazone group were lower than those in model group $(P<0.05$ or $P<0.01)$. INS: Before 
administration, the values of each group were all lower than those in blank group, only the value of model group was lower than that in blank group, the differences was significant $(P<0.01)$; compared with the model group, the values of high, medium, low alcohol group and rosiglitazone group were significantly higher, the differences were significant $(P<0.01)$. After administration, the value of model group was lower than that in blank group, the difference was significant $(P<0.01)$; the values of high, medium, low alcohol group and rosiglitazone group were all higher than those in the model group, the differences were significant $(P<0.01)$. Shown in table 1 .

Table 1 Weight and the content in FBG and INS effects of cortex lycii radicis ethanol-extract on $\mathrm{T} 2 \mathrm{DM}$ rats $(\overline{\mathrm{x}} \pm \mathrm{S})$

\begin{tabular}{|c|c|c|c|c|c|c|c|}
\hline \multirow{2}{*}{ Groups } & \multirow{2}{*}{$\mathrm{n}$} & \multicolumn{2}{|l|}{ Weight /g } & \multicolumn{2}{|c|}{$\mathrm{FBG} / \mathrm{mmol} \cdot \mathrm{L}^{-1}$} & \multicolumn{2}{|c|}{$\mathrm{INS} / \mathrm{mU} \cdot \mathrm{L}^{-1}$} \\
\hline & & $\begin{array}{c}\text { Before } \\
\text { administration }\end{array}$ & $\begin{array}{c}\text { After } \\
\text { administration }\end{array}$ & $\begin{array}{c}\text { Before } \\
\text { administration }\end{array}$ & $\begin{array}{c}\text { After } \\
\text { administration }\end{array}$ & $\begin{array}{c}\text { Before } \\
\text { administration }\end{array}$ & $\begin{array}{c}\text { After } \\
\text { administration }\end{array}$ \\
\hline $\begin{array}{l}\text { Blank control } \\
\text { group }\end{array}$ & 10 & $301 \pm 17$ & $408 \pm 21$ & $8.41 \pm 1.2$ & $8.73 \pm 1.3$ & $257.6 \pm 123.3$ & $263.7 \pm 105.6$ \\
\hline $\begin{array}{l}\text { Model control } \\
\text { group }\end{array}$ & 10 & $382 \pm 30^{\mathrm{a}}$ & $454 \pm 29$ & $20.12 \pm 2.75^{\mathrm{b}}$ & $17.22 \pm 2.43^{\mathrm{b}}$ & $136.2 \pm 31.4^{\mathrm{b}}$ & $141.3 \pm 21.5^{\mathrm{b}}$ \\
\hline $\begin{array}{l}\text { Rosiglitazone } \\
\text { group }\end{array}$ & 10 & $359 \pm 26^{a}$ & $448 \pm 23$ & $17.85 \pm 2.66^{\mathrm{b}}$ & $12.52 \pm 3.31^{\mathrm{a}, \mathrm{c}}$ & $251.7 \pm 46.5^{\mathrm{d}}$ & $247.3 \pm 52.3^{\mathrm{d}}$ \\
\hline $\begin{array}{l}\text { Low alcohol } \\
\text { group }\end{array}$ & 10 & $371 \pm 22^{\mathrm{a}}$ & $422 \pm 21$ & $18.77 \pm 2.49^{b}$ & $10.19 \pm 3.10^{\mathrm{d}}$ & $225.4 \pm 21.6^{\mathrm{d}}$ & $275.5 \pm 85.7^{\mathrm{d}}$ \\
\hline $\begin{array}{l}\text { Medium } \\
\text { alcohol group }\end{array}$ & 10 & $365 \pm 20^{\mathrm{a}}$ & $461 \pm 27$ & $19.23 \pm 3.08^{\mathrm{b}}$ & $11.71 \pm 3.21^{\mathrm{d}}$ & $236.5 \pm 48.2^{\mathrm{d}}$ & $282.4 \pm 76.1^{\mathrm{d}}$ \\
\hline $\begin{array}{l}\text { High alcohol } \\
\text { group }\end{array}$ & 10 & $374 \pm 25^{\mathrm{a}}$ & $467 \pm 30$ & $18.98 \pm 2.97^{\mathrm{b}}$ & $11.68 \pm 3.17^{\mathrm{d}}$ & $233.1 \pm 55.3^{\mathrm{d}}$ & $280.8 \pm 65.4^{\mathrm{d}}$ \\
\hline
\end{tabular}

Note: compared with the blank control group, ${ }^{\mathrm{a}} \mathrm{P}<0.05$, ${ }^{\mathrm{b}} \mathrm{P}<0.01$; compared with the model control group, ${ }^{\mathrm{c}} P<0.05$, ${ }^{\mathrm{d}} P<0.01$; compared with the rosiglitazone group, ${ }^{\mathrm{e}} P<0.05$, ${ }^{\mathrm{f}} P<0.01$ (Table 2 as the same as table 1 ).

The content inTC,TG and LDL-C effects of cortex lycii radicis ethanol-extract on T2DM rats. TC: After administration, the value of model group was higher than that in blank group, the difference was significant $(P<0.05)$; the values of high, medium , low alcohol group were all lower than those in model group, the differences were significant $(P<0.01)$. TG: Before administration, the values of each group were all higher than those in blank group, the differences were significant $(P<0.01)$.After administration: the values of model group and rosiglitazone group were higher than those in blank group, the differences were significant $(P<0.05$ or 0.01$)$; the values of high, medium, low alcohol group were all lower than those in model group and rosiglitazone group, the differences were significant $(P<0.01$ or 0.05$)$. LDL-C: Before administration, the values of each group were all higher than those in blank group, the differences were significant $(P<0.01$ or 0.05$)$; the values of high, medium, low alcohol group were all lower than those in model group, the differences were significant $(P<0.01$ or 0.05$)$. After administration: the value of model group was higher than that in blank group, the differences were significant $(P<0.01)$; the values of high, medium, low alcohol group and rosiglitazone group were all lower than those in model group, the differences were significant $(P<0.01)$. Shown in table2. 
Table 2 The content inTC,TG and LDL-C effects of cortex lycii radicis ethanol-extract on T2DM

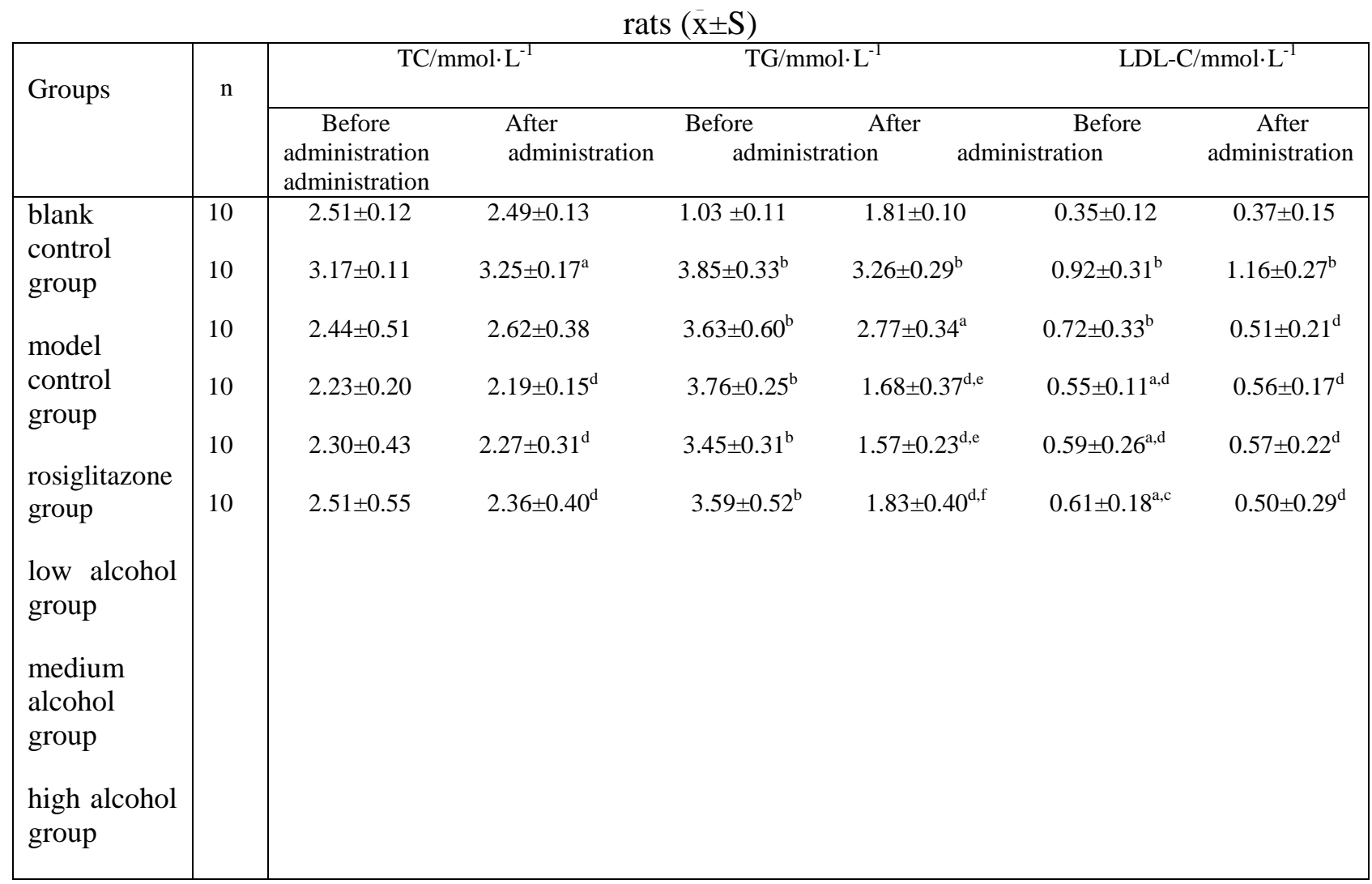

\section{Discussion}

T2DM is a metabolic disorders which main feature are elevated blood glucose levels and insulin resistance. Now, it is believed that the it's pathogenesis is mainly due to the dysfunction of pancreatic beta cell, which lead to are insulin resistance and insulin secretion less, the insulin secretion defects play a key role in the development of diabetes, it is the main reason of causing T2DM.Therefore, how to protect the pancreatic beta cell is the key research direction for prevention and treatment diabetes ${ }^{[6,8]}$.

Cortex lycii radicis is a kind of drug which commonly be used for the clinical treatment of diabetes and it's main components are alkaloids, organic acids and lipids, peptides, anthraquinone, diamide, steroids, glycosides, taurine, vanillic acid , and so on ${ }^{[9]}$. Existing studies have found that it's functions include stimulating the pancreatic beta cell to secrete more insulin ${ }^{[10]}$, reduce the damage to the morphological structure of pancreatic beta cells ${ }^{[5]}$, lowering blood sugar ${ }^{[11]}$, lowering blood fat and improving immune function ${ }^{[12]}$, and so on. And also found that the main components of lowering blood sugar are organic acids and alkaloids ${ }^{[1,13,14]}$.

The experimental results show that cortex lycii radicis ethanol-extract can reduce the weight of experiment rats, but it compared with the rats in the model group, the difference is not obvious; it can effectively reduce the FBG, compared with high, medium, alcohol group, low alcohol group had better effect, but there was no significant difference; it can increase the content of INS, low alcohol group had better effect. Compared with model group,TC,TG and LDL-C contents in the high, medium and low alcohol group were all significantly decreased, but the largest decline in the first and second indicator in low alcohol group, better effect of LDL-C content decreased in high alcohol group. But cortex lycii radicis ethanol-extract dose-response relationship of liquid is not obvious, different doses of cortex lycii radicis in different aspects demonstrates the superiority.

The experiment results show that the cortex lycii radicis ethanol-extract can effectively reduce the damage of STZ on the secretion of pancreatic beta cells in rats, protect and restore the function of pancreatic beta cells, effectively improve the status of insulin resistance and insulin secretion less, so as to play a role in lowering blood glucose, regulating blood lipid metabolism, which opened up 
a new way to find new drugs for lowering blood glucose. Ascertain cortex lycii radicis ethanol -extract how to affect the molecular target of pancreatic beta cells, which will become the further research direction in this field.

\section{References}

[1] Gao Dawei, Liu Zhiwei,Liu Zhihu. Hypoglycemic effect of Cortex Lycii Radieis extract and its analysis of compounds[J]. Journal of Yan shan University, 31(2007)269-272.

[2] Ning Na, Han Jianjun. Chemical constituents and pharmacological activities of Lycii Cortex[J]. Drugs\& Clinic, 25(2010)172-176.

[3] Yang Fengqin, Chen Shaoping, Ma Xueqin, et al. Experimental study on bacteriostasis effect of alcohol extracts from lycium barbarum L in vitro[J]. Ningxia Med J,29(2007) 787-789.

[4] Huang Xiaohong, Zhou Xingwang, Wang Qiang, et al. Effect of relieving-fever and reducing plasmas glucose of 3 kinds of Digupi on albino rats[J]. Journal of Fujian Agricultural University, 29(2000) 229-232.

[5] Shen Guiyue, Wen Yongzhi, Jin Zheng. Effects of Lycii Radicis on Immunohistochemical Changes in Pancreatic Islet Cells of Mice with Expermental Diabetes[J]. Journal of Medical Science Yanbian University, 13(1990)179-181.

[6] Wang Dong, Ye Zhen, Huang Qi. Effect and Mechanism of Cortex Lycii Radicis Extracts on the Proliferation and Apoptosis of Pancreatic Beta Cell [J]. Journal of Zhejiang Chinese Medical University, 39 (2015) 478-481.

[7] Wu Zhiqian, Hao Gaimei, Xue Xiaoxing, et al. Research on the effect of Gegenqinlian Decoction on type 2 diabetic model[J]. Global Traditional Chinese Medicine, 7(2014)161-167.

[8] Liu M, Jing D, Wang Y, et a1. Overexpression of angiotensin II type 2 receptor promotes apoptosis and impairs insulin secretion in rat insulinoma cells[J]. Molecular and celluar biochemistry, 400(2015) 233-244.

[9] Zhou Jie, Zhu Wei. Research Progress on chemical constituents and pharmacological of Digupi[J].SHANXI J OF TCM, 24(2008)47.

[10] Wei Zhiqing, Yu Hongchuan, Fan Ruijun. The Effective Components from Cortex Lycii for Reduction of Blood Sugar[J]. LISHIZHEN MEDICINE AND MATERIA MEDICA RESEARCH, 20(2009)848-850.

[11] Zhang Jing, Li Wanqing, Wu Aiqun. Efects of Digupi and Huangqi on insulin secretion[J]. HENAN MEDICAL RESEARCH, 9(2000)221-222.

[12] Yang Xiaofeng, Li Shenggang, Yu Dezhi, et al. EFFECTS OF CORTEX LYCII GRANULES CO. ON SERUM GLUCOSE, LIPID AND IMMUNOLOGIC FUNCTION[J]. MEDICAL JOURNAL OF QI LU, 15(2000)84-86.

[13] Li Kang, Bi Kaishun, Si Baoguo. Hypoglycemic Effects of Different Compositions of Cortex Lycii Radicis ( CLR) in Aalloxan Diabetic Mice[J]. CHINESE ARCHIVES OF TRADITIONAL CHINESE MEDICINE, 23(2005)1298-1299.

[14] Li Chunying, Jiang Haixia, Zhang Jing, et al. Study on extraction of effective components in Cortex Lycii and its hypoglycemic lipid-lowering effect[J]. Forest By-Product and Speciality in China, 4(2014)27-29. 